\title{
O Mundo, da Nossa Janela, aberto ao Infinito. Artes, Mulheres e Migrações
}

\author{
Paula Guerra1 \\ Maria da Graça Luderitz Hoefel ${ }^{2}$
}

Fernando Pessoa escreveu, algures no tempo, que não basta abrir uma janela para vermos os campos e os rios. Esse pequeno excerto permaneceu conosco e manifestou-se nos nossos pensamentos. Em certa medida, podemos dizer que a organização deste Dossiê surgiu de uma necessidade individual, de um sentimento que nos assolava há muito tempo e que se relacionava com a vontade de percebermos os movimentos que têm pautado as sociedades e as cidades. Estes movimentos, no nosso entender, são como fios invisíveis e movem-se à velocidade de um comboio TGV, o que faz com que nem sempre seja percetível a sua passagem. A velocidade é por vezes de tal ordem elevada que as bagagens se perdem pelos apeadeiros e outras vezes, os comboios se desalinham dos carris. Bagagens e comboios perdem-se. Pensando que desde o início do milénio, de forma mais ou menos acentuada, os movimentos migratórios têm vindo a aumentar um pouco por todo o mundo, imagine-se quantas bagagens já não se terão perdido ou quantos descarrilamentos terão acontecido. Quantos fios já não se cruzaram,

\footnotetext{
1 Doutora em Sociologia pela Universidade do Porto, Portugal. É professora na Faculdade de Letras (FLUP) e investigadora do Instituto de Sociologia da mesma universidade (IS-UP). É ainda investigadora do Griffith Center for Social and Cultural Research (GCSCR) na Austrália, do Centro de Estudos de Geografia e do Ordenamento do Território (CEGOT), do Centro de Investigação Transdisciplinar «Cultura, Espaço e Memória» (CITCEM) e do Centro de Estudos sobre a Mudança Socioeconómica e o Território (DINÂMIA'CET - IUL). Coordena e participa em vários projetos de investigação nacionais e internacionais, no âmbito das culturas juvenis e da sociologia da arte e da cultura. É autora de artigos publicados em revistas como Critical Arts, European Journal of Cultural Studies, Journal of Sociology, Cultural Sociology, Cultural Trends, Sociologia - Problemas e Práticas ou Revista Crítica de Ciências Sociais. É editora (em conjunto com Lígia Dabul) da revista Todas as Artes. Revista Luso-Brasileira de Artes e Cultura. Universidade do Porto, Faculdade de Letras e Instituto de Sociologia, Porto, Portugal. E-mail: pguerra@letras.up.pt. ORCID: 0000-0003-2377-8045.

2

Professora do Departamento de Saúde Coletiva da Universidade de Brasilia (UnB). Coordenadora do Laboratório de Saúde do Trabalhador, Saúde Indígena e Saúde dos Migrantes. Coordenadora do Projeto Vidas Paralelas Migrantes/UnB. Investigadora Colaboradora do Centro de Investigação Transdisciplinar «Cultura, Espaço e Memória» (CITCEM). Email: gracahoefel@gmail.com. ORCID: 0000-0003-2176-5013.
} 
metáforas, podemos referir Eduardo de la Fuente (2019). Na exata medida em que este sociólogo introduz na sua pesquisa o conceito de textura, como uma metáfora e de certo modo, como uma oposição a abordagens clássicas ou convencionais da sociologia da cultura e das artes. Este conceito surge como uma forma de referenciar as dinâmicas ou aspetos da vida social que são difíceis de serem captados, o que vai exatamente ao encontro da nossa perspetiva. Texture faz alusão ao têxtil, dado que um tecido é composto por muitos fios, representando assim, a complexidade das relações sociais, servindo então, este conceito, para analisar as materialidades e ordens espaciais e temporais que compõem a realidade.

É na senda destes emaranhados que surgem novas matrizes sociais, culturais e geográficas. Novos cruzamentos e destinos. Apesar de os dados sobre os movimentos migratórios serem regularmente apresentados e trabalhados, não conseguimos deixar de sentir que são apenas isso mesmo, dados. Números desprovidos de sentidos, de pulsações e ancestralidades, incapazes de captar as criações e vidas existentes por detrás dos eventos mensurados. Dados vazios de significados simbólicos, que muita vezes mais calam do que falam. Todavia, cada evento possui texturas, isto é, múltiplos detalhes e relações que lhe conferem caráter enquanto evento. Estas teorias acerca da vida social, devem centrar-se nos movimentos e padrões de crescimento dos materiais, perceções sensoriais e relações humanas (Fuente, 2019). Esta perspetiva de Eduardo de la Fuente remeteu-nos para outro pensamento, o da própria visão e experimentação do mundo. Leva-nos a encontrar metáforas que possam explicar as nossas assunções. É quase como se o mundo fosse a nossa rua e nós apenas o estivéssemos a ver da janela. Vemos quem passa, sem the desejar bom dia e sem perguntar se está tudo bem com o/a vizinho/a. Olhámos, mas não vemos e nem sequer temos tempo para parar e tentar ver. Este pensamento, ou este olhar "janeleiro" - como já dizia Erving Goffman (1999) nos seus trabalhos pioneiros - revela-se de forma ainda mais afoita se nos focarmos nas mulheres. Nas nossas vizinhas de porta 
as vemos a passar na rua, nem nos carris da vida por estarmos demasiado presos aos afazeres, às nossas tarefas e concentrados em aproveitar a rapidez com que decorre a vida quotidiana citadina (Pais, 2010). E não queremos ver, e talvez seja por isso que no campo académico, mediático e político, as mulheres persistem invisibilizadas.

$\mathrm{Na}$ verdade, este é o grande problema das nossas janelas. Enquanto herdeiras da modernidade, do colonialismo e do eurocentrismo - limitam-nos os olhares e o conhecimento. Impedem os delocamentos culturais, epistemológicos e políticos inerentes à capacidade de reconhecer a existência de outros modos de ver, interpretar e interagir com o mundo. Limitam-nos os olhares e o conhecimento. São caixilhos e portadas que nos prendem a uma realidade que é palpável, mas que não é completa, porque é apenas nossa. A partir deste breve questionamento existencial - bem à moda filosófica - surgem as pontes com os artigos que lemos e com a nossa bagagem teórica. Pensando nos contributos teóricos que vão ao encontro das nossas interrogações, o conceito de decolonial é fundamental (Ascione, 2016), porque implica ver a rua, mas a partir da janela de outra pessoa. É um trocar de perspetivas que pode fazer com que se vejam as cores da calçada e os destinos que, caso contrário, não seria possível. Num olhar bem sociológico, implica ir mais além e questionar os motivos que subjazem as escolhas de partir, de ficar ou de querer fazer melhor e diferente. Mais ainda, perceber as relações que se criam com os locais, com as regiões e com os espaços que são habitados. Os novos e os antigos.

As migrações são uma estratégia antiga de melhoria das condições de vida (Duda-Mikulin, 2020), bem como as artes são historicamente uma forma de expressão e um meio de resistência (Guerra, 2021). A natureza volátil das identidades é ainda mais intensificada quando refletimos acerca dos papéis e dos laços sociais que marcam a vida num país novo (Hall \& Jefferson, 1993), uma vida que é vista a partir de outras janelas. Com esta compilação, era nossa intenção romper com os estudos efetuados em torno destes 
processos imigratórios, parecem seguir uma tendência de neutralidade do ponto de vista do género (Duda-Mikulin, 2020), classe e raça/etnia não tendo em consideração as especificidades inerentes a homens e mulheres, mas também ao nível das faixas etárias, e até mesmo atendendo às diferentes nacionalidades e apropriações culturais e políticas.

Segundo o World Migration Report 2020 da Organização Internacional para as Migrações (2019), no cenário global, o número de migrantes internacionais em 2019 chegou aos 277 milhões, sendo que 74\% dos migrantes estavam em idade ativa (20-64 anos). Concomitantemente, vários autores e organizações indicam que há um processo de feminização da migração e de mudança do perfil da mulher migrante. Nestes trânsitos e fluxos, as desigualdades de género persistem e permanecem invisibilizadas, tal qual as particularidades dos reais universos simbólicos, culturais e sociais vivenciados por estas mulheres nos seus quotidianos dos países de destino. Apesar disso, as mulheres migrantes resistem e reinventam suas vidas. Representam uma geração conectada e globalizada, que estabelece outras formas de relações sociais, permeadas por linguagens imagéticas, artísticas e tecnológicas intensas. $\bigcirc$ acionamento destes capitais tem permitido a dinamização de processos articulados em redes e atravessados por expressões artísticas que visam o enfrentamento de iniquidades, revelando um ativismo estético-político pulsante que sinaliza potencialidades expressivas para a evocação de demandas da realidade e alinha-se com o cenário global. De facto, as manifestações sociais mundo afora evidenciam a diversidade de expressões reveladas em graffiti, performances, música, literatura, ocupações urbanas, entre outras, presentes em inúmeros países protagonizadas por mulheres migrantes. Com este Dossiê, queremos destacar experiências artísticas e de ativismo estético-político levadas a cabo por mulheres migrantes considerando que as suas expressões têm sinalizado as potencialidades das artes enquanto dispositivos capazes de trazer à luz universos silenciados e possibilitar a recriação incessante de identidades. 

entender, são uma forma de mitigar essas perdas, no sentido em que colmatam o sentimento de perda, de abandono e os contextos de incerteza (GUERRA et al., 2020). As artes são quase o destino não esperado. São as descobertas. São liberdade. Assim, são estas bagagens artísticas que se criam pelos caminhos que são percorridos, e pelos movimentos que são feitos. A bagagem artística, representa uma geração que se relaciona com novas formas de relações sociais, pautadas por linguagens imagéticas, artísticas e tecnológicas, até porque persiste uma ideia de que as mulheres migrantes são pobres e com baixos níveis de escolaridade (SEPPÄLÄ, 2016). Estas bagagens vêm desmentir esta ideia. No fundo, transmitem-nos uma mensagem de que os seus movimentos e os caminhos que estas mulheres percorrem pelos caminhos da vida são, na verdade, partes do processo de transformação da mulher em arte. Ser mulher migrante implica tornar-se em arte. Ser e fazer da vida uma arte. São locus de transformação. Estes percursos e viagens artísticas que se fazem, na azáfama da vida quotidiana, são fruto de um processo eurocêntrico de imposições que fizeram com que se criasse uma noção canónica do que é a arte, e do que esta representa nas vidas e nas identidades. Neste Dossiê, falámos das artes de viver, de sentir e de resistir. Falámos de espaços e de práticas que vão além de uma moldura exposta num museu, e que têm no seu âmago as trivialidades, nomeadamente os objetos, as roupas, as palavras e os gestos (MORPHY, 2007). Desta feita, uma abordagem transcultural às práticas artísticas destas mulheres tornou-se num dos pontos nodais deste Dossiê, especialmente pelo facto de pretendermos dar conta da vida social das artes (ROGERS, 2017).

É com estas três pontas que vão desfilar os treze artigos: artes, mulheres e migrações. Cada um deles uma viagem, uma bagagem e um fio que se cruza e entrecruza. A primeira paragem destas viagens faz-se com o artigo de Henrique Grimaldi que interliga a mulher migrante e a moda, criando debates e reflexões em torno dos métodos de consagração e o êxito das carreiras artísticas. No fundo, o autor procura recuperar as formas como 
serdem certas bagagens, mas outras surgem em sua substituição, partindo dos acervos da Fondation Louis Vuitton em Paris. Analisa a forma como o movimento leva ao reconhecimento e à validação de uma obra artística, ao passo que contribui para um entendimento efetivo dos processos de consagração artística. Tendo como mote a geografia e os valores simbólicos, o autor debruça-se sobre um recorte de género, nomeadamente de artistas colecionadas pela Fondation Louis Vuitton, em Paris, levando-nos, pela mão, pelos jogos da arte (BOURDIEU, 1996).

Partindo deste ponto, fazemos uma viagem no tempo, entre os lugares do passado e os novos conquistados. Paula Guerra com o artigo "Continuarei em busca do meu lugar. Mulheres, migrações e música", vê da sua janela - a história de vida da música Flávia Couri. Vê atentamente, e com particular interesse, a forma como a sua experiência de emigração se casa com a música, com os processos de globalização, mas também com as cenas musicais locais e translocais. Analisa as formas como as artes, neste caso a música, lhe proporcionaram novas bagagens essenciais para que a artista (migrante) fosse capaz de navegar por entre os mares da volatilidade identitária. Neste artigo, a vista da janela dá lugar a uma conversa no alpendre, origina um lugar de aproximação em que a discussão ganha um palco e a partilha uma voz escrita e falada, que resulta do cruzamento entre o individual e o translocal, cruzamentos de estéticas e que origina um lugar, ocupado por Flávia, no seio da música.

Rachel Pereira da Silva Souza, com "Cassi Namoda: Versões da Moçambique pós-colonial" pintamos uma viagem ao passado. Passado esse conturbado e marcado por movimentos duplos, de entradas e de saídas. A autora fala-nos de uma jovem artista de Moçambique, Cassi Namoda, que vive entre janelas. Vive entre movimentos. Entre Los Angeles e Nova York, mas que nunca deixa de estar com um pé no seu país de origem, levando-o sempre consigo, na sua bagagem de mão. Nas suas obras - na pintura retrata a complexidade de se ser mulher, ainda mais uma mulher imigrante que está em todo o lado e, ao mesmo tempo, presa a um só local. Além 
as suas viagens é esclarecedor pois, com o pincel, a artista enfrenta a história do seu país, desde o colonialismo à revolução, visto através do seu outro eu, o seu alter ego.

Lindomberto Alves apresenta a materialização das visões da janela. Retrata uma cartografia provisória de uma viagem artística trilhada pela artista Rubiane Maia, ao longo de dez anos. Este artigo traz consigo a descoberta do que é viver e reviver, sempre em locais diferentes. É a materialização dos fluxos constantes da vida, em que a arte é o passaporte e o bilhete de acesso a uma condição histórica trespassada no corpo e nos quotidianos da artista. Assim, demonstra-nos como estas trivialidades regem as relações sistémicas das artes. Um pouco na mesma lógica temos André Pitol, que se foca no percurso migratório de Madalena Schwartz, uma fotógrafa húngara que fez morada no Brasil, na década de 1960. O autor aborda uma vida de movimentos e de estadias efémeras. Retrata também um cruzamento de vivências, plasmado em Budapeste, Buenos Aires e São Paulo. Para esta mulher, a fotografia foi a sua casa, bem como o seu enquadramento dinâmico e vivencial, pois retrata as suas trajetórias.

Laura López Casado analisa o fanzine como uma fronteira habitada. Como um espaço em que o movimento e a fixação convergem, dando origem ao surgimento de objetos artísticos que se encontram nas margens. A autora vem demonstrar que o fanzine pode ser tido como um espaço de reflexão, como uma arma. Visa demonstrar que nem todas as mulheres são invisíveis e que as suas histórias e vivências importam, mas também refletem os olhares dos outros e as formas como os mesmos as afetam. Mas acima de tudo, revelam os meios que estas encontram para resistirem. Nesta lógica, Ondina Pires em "Migração a preto e branco: o trabalho artístico de Kara Walker", leva-nos - tal como Rachel Pereira da Silva Souza - a uma viagem ao passado. Em particular a um passado em que as condições de vida dos afroamericanos eram complexas e tumultuosas. Tomando de assalto os trabalhos da artista Kara Walker, nomeadamente, trabalhos de assemblages, instalações 
migração forçada de milhões de africanos rumo às Américas.

Ashjan Adi, Muna Muhammad Odeh, Soraya Misleh, Elizabeth Hazin, Oula Al Saghir, conjugam cinco estórias de mulheres palestinas e descendentes de palestinos, que foram obrigadas a deixar a sua casa. No fundo, vão ao encontro do olhar sociológico e centram-se nos motivos por detrás dos movimentos. Dado os acontecimentos atuais que marcam o quotidiano dos palestinianos, os autores analisam o mosaico de fios que inicialmente abordávamos. Falam da textura (FUENTE, 2019) de uma vida, o sofrimento, a luta, mas também a resistência. Por sua vez, Andréia Paulina Costa detém-se nas poéticas das artistas Mira Schendel, Anna Maria Maiolino e Liliana Porter, demonstrando a viagem e o movimento na primeira pessoa. A autora apresenta o deslocamento e a viagem pela palavra escrita. Palavra essa que advém de rastos de vivências históricas, sociais e políticas e que se manifestam sobre a forma de memórias, no nosso presente.

Cacilda Reis enuncia e reflete sobre os motivos da migração, bem como a forma como estes interferem nos movimentos e nas suas cimentações. Nesse sentido, a autora foca-se no trabalho de dançarinas afrobrasileiras na França, ao passo que procura conhecer quais as singularidades do campo artístico, e a forma como estes movimentos se inserem nos mercados de trabalho. Paralelamente são ainda retratadas as vivências destas mulheres, quais os seus objetivos e as suas aspirações, demonstrando que estas não são invisíveis e que existem mais informação, além daquela que os nossos olhos vêm. Em "Expressões Imagéticas e Migração", Juliane Peixoto Medeiros, aborda em maior profundidade esta questão da invisibilidade, dando conta da condição de mulher negra da artista e teórica portuguesa Grada Kilomba. Ao longo do artigo aborda temas como o colonialismo, os quotidianos, o racismo e os diálogos, ou seja, as faces ocultas das estórias e dos movimentos que marcam um período histórico, mas também social no contexto do Sul Global. Desvenda as camadas que mapeiam a inserção e a vida em comunidade, colocando a tónica nos diálogos e nos imaginários, enquanto amplificadores de vozes e transformativos de modelos de poder. 
Paula Guerra, Maria da Graça Luderitz Hoefel, Denise Osório Severo e Sofia Sousa, fornecem um recorte de investigação que visa promover uma discussão em torno do ativismo estético-político, e o papel que a música desempenha nas formas de expressão das lutas pela igualdade. Falam-nos de trânsitos, de movimentos e de experimentações. Vão ao intimo das casas e das vivências das mulheres, bem como demonstram os caminhos percorridos, refletindo em que medida a música influencia os processos de emancipação social. Assim, centram-se na análise das experiências de duas mulheres brasileiras artistas, nas suas experiências e percursos, ao passo que abordam as dificuldades que as mesmas sentiram desde cedo, para se conseguirem inserir no mundo artístico. Por último, em "Viagens feitas de Sons. Contributos para uma (re)escrita de diásporas de mulheres imigrantes de leste em Portugal", é feita uma reflexão em torno da relação entre a música e as representações de mulheres romenas imigrantes em Portugal, talvez um dos grupos que mais bagagens perdem no decorrer das suas viagens. Os autores do artigo, Paula Guerra, Sofia Sousa e João Carlos Lima, demonstram-nos que a música é uma componente do dia-a-dia das mulheres, é o que Ihes trilha o caminho e mapeia os seus carris da vida, destacando o seu papel enquanto meio de resistência, de sobrevivência e de afirmação.

\section{Referências}

BOURDIEU, Pierre (1996). As regras da arte: Gênese e estrutura do campo literário. São Paulo: Cia das Letras.

DUDA-MIKULIN, E. (2020). Gendered migrations and precarity in the postBrexit-vote UK: the case of Polish women as workers and carers. Migration and Development, 9(1), 92-110.

FUENTE, de la Eduardo. (2019). After the cultural turn: For a textural sociology. The Sociological Review, 67(3), 552-567.

GOFFMAN, Erving (1999). The Presentation of Self in everyday Life. UK: anchor Books/Doubleday. 
GUERRA, Paula (2020). Elogio da improbabilidade do património. In Oliveira, Gerciane Maria da Costa \& Vieira, Kyara Maria de Almeida (Eds.). Patrimônio, povos do campo e memórias: diálogos com a cultura, a arte e a educação. Mossoró: EdUFERSA.

GUERRA, Paula \& ALBERTO, Thiago Pereira (2021). Welcome to the 'modern age': The imagery of punk from the 1970s in the redefinition of the New York music scene of the 2000s and beyond. In BESTLEY, Russ; DINES, Mike; GUERRA, Paula \& GORDON, Alastair (Eds.). Trans-Global Punk Scenes. The Punk Reader Volume 2. Fishponds, Bristol: Intellect Books.

GUERRA, Paula; HOEFEL, Graça Maria da; SEVERO, Osório; Denise \& SOUSA, Sofia (2020). Women on the Move. Contributions to the aestheticpolitical activism approach of Brazilian migrant women. Cahiers du MIMMOC. Mémoire(s), identité(s), marginalité(s) dans le monde occidental contemporain [Em Linha]. v. 21, colocado em linha em 17 de agosto de 2020, consultado em 18 de agosto de 2020.

GUERRA, Paula \& MENEZES, Pedro (2021). So far, so close: Contemporary faces of Portuguese and Brazilian punk scenes. In BESTLEY, Russ; DINES, Mike; GUERRA, Paula \& GORDON, Alastair (Eds.). Trans-Global Punk Scenes. The Punk Reader Volume 2. Fishponds, Bristol: Intellect Books.

GUERRA, Paula \& QUINTELA, Pedro (Eds.) (2020). Punk, fanzines and DIY cultures in a global world. Fast, furious and xerox. London: Palgrave Macmillan.

HALL, Stuart, \& JEFFERSON, Tony (1993). Resistance through rituals: youth subcultures in post-war Britain. London: Routledge.

MORPHY, Howard (2007). Becoming Art. Exploring Cross-Cultural Categories. London: Routledge.

PAIS, José Machado (2010). Lufa-Lufa Quotidiana. Ensaios sobre cidade, cultura e vida urbana. Coimbra: Coleção Breve.

ROGERS, Amanda (2017). Material migrations of performance. Royal Geographical Society. Disponível em: https://rgs-ibg.onlinelibrary.wiley.com/ doi/epdf/10.1111/area.12338

SEPPÄLÄ, Tiina (2016). Feminizing resistance, decolonizing solidarity: Contesting neoliberal development in the Global South. Journal of Resistance Studies, 1 (2). 